\title{
Recurrent copy number variants associated with bronchopulmonary dysplasia
}

\author{
Ausaf Ahmad ${ }^{1,2}$, Soumyaroop Bhattacharya ${ }^{1,2}$, Arthi Sridhar ${ }^{3}$, Anwar M. Iqbal ${ }^{3}$ and Thomas J. Mariani ${ }^{1,2}$
}

BACKGROUND: Variability in the incidence and severity of bronchopulmonary dysplasia (BPD) among premature infants suggests that genetic susceptibility plays a role in pathogenesis. An assessment of copy number variants (CNV) in BPD subjects may help to identify loci that harbor genetic susceptibility factors.

METHODS: We conducted a retrospective analysis of clinical DNA microarray data from our institution. We identified 19 BPD subjects, and 2 controls groups (full-term and preterm) with no lung-related disease. We reanalyzed raw data from each of these subjects to identify recurrent CNV loci in BPD subjects.

RESULTS: We identified three loci (at 11q13.2, 16p13.3, and 22q11.23-q12.1) with recurrent CNV in BPD subjects. The frequency of these CNV was significantly higher in BPD subjects when compared with at least one control group. We interrogated 21 genes residing within the recurrent CNV regions for development-associated changes in expression. Fifteen genes demonstrated significant changes in expression between the pseudoglandular and canalicular stage in human lungs, a time commensurate with birth at highest risk for BPD. We also identified pathways represented by the genes present within the recurrent loci.

CONCLUSION: These data identify novel loci that may harbor genes contributing to the genetic susceptibility of BPD.

B ronchopulmonary dysplasia (BPD) is common in premature babies born before 29 wks of gestational age and weighing less than $2.2 \mathrm{lb}$ (1). Each year, approximately 500010,000 babies born in the United States receive a diagnosis of BPD. The rate of preterm birth $(\sim 12 \%)$ in the United States is higher than other developed countries (2). The number of BPD cases has increased over the last decades, largely due to higher survival rates of premature infants. Very-low-birthweight premature infants, born during the canalicular and saccular stages of lung development, are at the greatest risk of $\mathrm{BPD}$ due to disruptions in the normal program of lung alveolar and vascular development $(3,4)$. More than $30 \%$ of premature infants born before 30 wks of gestational age develop BPD (3) and almost all infants ( $>97 \%$ ) with birth weight $<1,250 \mathrm{~g}$ are diagnosed with BPD (5).

A diagnosis of BPD is dependent upon the use of supplemental oxygen following preterm birth. In addition to premature birth, environmental factors such as oxidative stress, mechanical ventilation, and infection play a significant role in pathogenesis of BPD. Higher than physiological levels of therapeutic oxygen (hyperoxia) induce stress with production of reactive oxygen species. The lungs of premature infants are susceptible to injury with pre- and postnatal exposures. These exposures may cause lung damage and induce a deviation from the normal developmental path (4).

Variability in the incidence and severity of BPD among premature infants with similar risk factors suggests that genetic susceptibility plays a significant role $(6,7)$. After controlling for covariates, genetic factors appear to account for a majority of the variance in liability for BPD in premature infants (7-9). Several previous studies have identified an association between candidate gene variants and BPD. Most of these studies have focused on genes for innate immunity, antioxidant defenses, mechanism of vascular remodeling, and genes coding for surfactants proteins $(5,10)$. While many significant findings have been reported, a majority of them have not been replicated in subsequent cohorts $(5,6)$. Genome-wide gene expression microarray studies identified numerous genes in BPD lung tissue which involved different pathways including DNA damage, regulation of cell cycle, B-cell development, inflammatory, cell proliferation, and hedgehog signaling $(11,12)$. More recently, genome-wide approaches to identify BPD susceptibility genes have been reported. SPOCK2 was identified as a susceptibility gene in a genome-wide association study (13). However, recent genome-wide association studies failed to replicate any of the previously identified genes, or identify any new candidate susceptibility genes at genome-wide significance $(14,15)$.

Genetic structural variations in the human genome range from single nucleotide polymorphisms to large chromosomal anomalies (16). Copy number variants (CNV) are large genomic structural changes resulting in an increase or decrease in the number of alleles for specific genes. $\mathrm{CNV}$

'Division of Neonatology, Department of Pediatrics, University of Rochester Medical Center, Rochester, New York; ${ }^{2}$ Department of Pediatrics, Pediatric Molecular and Personalized Medicine Program, University of Rochester Medical Center, Rochester, New York; ${ }^{3}$ Department of Pathology \& Laboratory Medicine, University of Rochester Medical Center, Rochester, New York. Correspondence: Thomas J. Mariani (Tom_Mariani@urmc.rochester.edu)

Received 9 July 2015; accepted 5 December 2015; advance online publication 23 March 2016. doi:10.1038/pr.2016.23 
regions are associated with several human diseases (e.g., neurodevelopmental disorders, congenital abnormalities, and cancer) $(17,18)$. For this reason, clinical DNA microarrays are widely used as a first-tier diagnostic test for CNV screening of patients who are suspected for chromosomal aberrations (19), particularly in the cases of congenital and/or newborn disease.

There is no prior report of CNV identification in BPD using DNA microarrays. We hypothesized that a genome-wide assessment of CNV in subjects with a diagnosis of BPD will help to identify specific loci that harbor genetic susceptibility factors. We conducted an IRB-approved retrospective analysis, using clinical DNA microarray database from our institution, and identified recurrent $\mathrm{CNV}$ in BPD subjects. We interrogated genes present within identified $\mathrm{CNV}$ regions for differential expression using previously published data sets describing genome-wide expression in developing human lung tissue (20). We further looked for pathways and processes represented by genes residing within CNV regions.

\section{RESULTS}

\section{Identification of Recurrent CNV Regions in BPD Subjects}

We identified and considered genic CNV (within RefSeq transcription boundaries), rare $\mathrm{CNV}(<1 \%$ frequency in normal population), and common polymorphic $\mathrm{CNV}$ ( $>1 \%$ frequency in the normal population). We identified 3 chromosomal regions (11q13.2, 16p13.3, and 22q11.23-q12.1) that contained a CNV in more than 1 of the 19 confirmed BPD subjects (Table 1). The Database of Genomic Variants showed that two of these three recurrent CNV loci (11q13.2 and 16p13.3) were rare $(<1 \%$ frequency in healthy populations). The remaining $\mathrm{CNV}$ region, encompassing 22q11.23-q12.1, involved rare (22q11.23) and common (q12.1) CNV regions. We further interrogated CNV at all these recurrent regions, since recent studies have shown that polymorphic regions have important functional consequences and are associated with disease susceptibility $(18,21)$.
Locus chr11q13.2. We identified recurrent deletions at chr11q13.2 in 3 out of 19 BPD subjects (15.8\%). The size range of these CNV regions was between 1.1 and $165.4 \mathrm{~kb}$ and included genes for GPR152, CABP4 (OMIM: 608965), AIP (OMIM: 605555), TMEM134, PITPNM1 (OMIM: 608794), CDK2AP2, C11orf72, CABP2 (OMIM: 607314), GSTP1 (OMIM: 134660), and NDUFV1 (OMIM: 161015) (Table 2 and Supplementary Figure S1 online). CNV at this locus were not found in any subject from either the full-term or preterm control groups. The frequency of this $\mathrm{CNV}$ was statistically significant between BPD and full-term control group ( $P$ value $=0.028)$. There was a trend for significance in the frequency of CNV at this locus between BPD and preterm control group $(P$ value $=0.084)($ Table 1$)$.

Locus chr16p13.3. We identified recurrent deletions at chr16p13.3 in 4 of 19 BPD subjects (21.0\%). The size of these $\mathrm{CNV}$ regions was between 15.5 and $33.7 \mathrm{~kb}$, and involved the hemoglobin locus. Genes within the locus affected by $\mathrm{CNV}$ included HBM (OMIM: 609639), HBA1 (OMIM: 141800), HBA2 (OMIM: 141850), HBQ1 (OMIM: 142240), and LUC7L (OMIM: 607782) (Table 3 and Supplementary Figure S2 online). CNV at this locus were observed in two full-term control subjects, but not in any of the preterm controls. There was a trend for significance in the frequency of CNV at this locus in BPD subjects as compared with full-term control group $(P$ value $=0.074)$. The frequency of this $C N V$ was statistically significant between BPD and preterm control group $(P$ value $=$ 0.035) (Table 1).

Locus chr22q11.23-q12.1. We identified deletions and duplication in two adjacent CNV regions at 22q11.23-q12.1 in three BPD subjects (15.8\%), ranging in size from 114 to $208 \mathrm{~kb}$. The gap between two CNV regions is approximately $1.9 \mathrm{Mb}$. The CNV regions included genes for BCR (OMIM: 151410), ZDHHC8P1, CES5AP1, CRYBB2P1, IGLL3P, and LRP5L

Table 1. Summary of recurrent CNV regions identified in BPD subjects

\begin{tabular}{|c|c|c|c|c|}
\hline Locus & $\begin{array}{l}\text { BPD } \\
(n=19)\end{array}$ & Gene & $\begin{array}{l}\text { Full-term control: } \\
(n=41) ;(P \text { value })\end{array}$ & $\begin{array}{l}\text { Preterm control: } \\
(n=23) ;(P \text { value })\end{array}$ \\
\hline Chr11q13.2 & 3 & $\begin{array}{l}\text { GPR152, CABP4, TMEM134, AIP, PITPNM1, CDK2AP2, CABP2, GSTP1, } \\
\text { C1 1 orf72 and NDUFV1 }\end{array}$ & $0 ;(0.028)$ & $0 ;(0.084)$ \\
\hline Chr16p13.3 & 4 & $\mathrm{HBM}, \mathrm{HBA} 1, \mathrm{HBA} 2, \mathrm{HBQ} 1$ and $\mathrm{LUC7L}$ & $2 ;(0.074)$ & $0 ;(0.035)$ \\
\hline Chr22q11.23-q12.1 & 3 & BCR, ZDHHC8P, CES5AP1 IGLL3, LRP5L and CRYBB2P1 & $0 ;(0.028)$ & $2 ;(0.644)$ \\
\hline
\end{tabular}

*Fisher's exact $t$-test.

BPD, bronchopulmonary dysplasia; CNV, copy number variants.

Table 2. Summary of recurrent CNV locus at chr11q13.2 identified in three BPD subjects and their clinical indications

\begin{tabular}{|c|c|c|c|c|c|c|c|}
\hline Clinical indication & Start & Stop & $\begin{array}{l}\text { Size } \\
(k b)\end{array}$ & $\begin{array}{l}\text { Number } \\
\text { of probes }\end{array}$ & $\begin{array}{l}\text { CNV } \\
\text { type }\end{array}$ & $\begin{array}{l}\log 2 \\
\text { ratio }\end{array}$ & Gene \\
\hline Congenital anomaly & 67213624 & 67378980 & 165.3 & 14 & Del & -0.414 & $\begin{array}{c}\text { GPR152, CABP4, TMEM134, AIP, } \\
\text { PITPNM1, CDK2AP2, CABP2, GSTP1, } \\
\text { C11 orf72, NDUFV1 }\end{array}$ \\
\hline Congenital anomaly & 67377880 & 67378980 & 1.1 & 4 & Del & -0.740 & NDUFV1 \\
\hline Tetralogy of fallot and tracheoesophageal fistula & 67377880 & 67378980 & 1.1 & 4 & Del & -0.719 & NDUFV1 \\
\hline
\end{tabular}

BPD, bronchopulmonary dysplasia; CNV, copy number variants. 


\section{Articles | Ahmad et al.}

(Table 4 and Supplementary Figure S3 online). We did not observe any $\mathrm{CNV}$ at this locus in the full-term control group, but observed CNV at this locus in 2 out of 23 preterm control group. The frequency of CNV at this locus was significantly higher $(P<0.05)$ in BPD subjects when compared with the full-term control group $(P=0.028)$, but not with the preterm $(P=0.644)$ control group (Table 1$)$.

Expression of $C N V$ genes in human lung development. We assessed expression of genes within the CNV loci in normal human lung development using our previously published expression database (20). We interrogated 21 genes within the 3 recurrent $\mathrm{CNV}$ regions for differential expression. In total, 15 genes $(71.4 \%)$, demonstrated significant changes $(P<0.05)$ in expression between the pseudoglandular and the canalicular stages of lung development, approximately at the time of preterm birth for subjects with the greatest risk of BPD (Figure 1). Eight genes within the 11q13.2 CNV locus displayed significant changes in expression; four genes (CABP4, CABP2, $\mathrm{CDK} 2 \mathrm{AP} 2$, and C11orf72) showing increases in expression and four genes (TMEM134, AIP, GSTP1, and NDUFV1) showing decreases in expression. Five genes within the 16p13.3 CNV locus (HBM, HBA1, HBA2, HBQ1, and LUC7L) showed significant decreases in expression. Two genes (BCR and LRP5L) within the 22q11.23-q12.1 locus displayed significant changes in expression; with LRP5L being increased and BCR decreased.

Table 3. Summary of recurrent CNV locus at chr16p13.3 identified in four BPD subjects and their clinical indications

\begin{tabular}{|c|c|c|c|c|c|c|c|}
\hline Clinical indication & Start & Stop & $\begin{array}{l}\text { Size } \\
(\mathrm{kb})\end{array}$ & $\begin{array}{l}\text { Number } \\
\text { of probes }\end{array}$ & $\begin{array}{l}\text { CNV } \\
\text { type }\end{array}$ & $\begin{array}{l}\text { Log2 } \\
\text { ratio }\end{array}$ & Gene \\
\hline Congenital anomaly & 215724 & 231196 & 15.5 & 11 & Del & -0.736 & $\begin{array}{l}\mathrm{HBM}, \mathrm{HBA} 2 \\
\mathrm{HBA} 1, \mathrm{HBQ} 1\end{array}$ \\
\hline Congenital anomaly & 215724 & 231196 & 15.5 & 11 & Del & -0.611 & $\begin{array}{l}\mathrm{HBM}, \mathrm{HBA} 2 \\
\mathrm{HBA} 1, \mathrm{HBQ} 1\end{array}$ \\
\hline $\begin{array}{l}\text { Perinatal history (prematurity, oligohydramnios), growth (short stature), } \\
\text { developmental delay, genitourinary (hydronephrosis, kidney malformation) }\end{array}$ & 215724 & 231196 & 15.5 & 11 & Del & -0.498 & $\begin{array}{l}\mathrm{HBM}, \mathrm{HBA} 2 \\
\mathrm{HBA} 1, \mathrm{HBQ} 1\end{array}$ \\
\hline
\end{tabular}

BPD, bronchopulmonary dysplasia; CNV, copy number variants.

Table 4. Summary of recurrent CNV locus at chr22q11.23-q12.1 identified in three BPD subjects and their clinical indications

\begin{tabular}{|c|c|c|c|c|c|c|c|}
\hline Clinical indication & Start & Stop & $\begin{array}{l}\text { Size } \\
(\mathrm{kb})\end{array}$ & $\begin{array}{l}\text { Number } \\
\text { of probes }\end{array}$ & $\begin{array}{l}\text { CNV } \\
\text { type }\end{array}$ & $\begin{array}{l}\text { Log2 } \\
\text { ratio }\end{array}$ & Gene \\
\hline $\begin{array}{l}\text { Prematurity; failure to thrive; short stature; fine motor delay; gross motor delay; } \\
\text { speech delay; hypotonia; structural brain anomaly (Dandy-Walker Syndrome) }\end{array}$ & 25695469 & 25903543 & 208.1 & 4 & Del & -3.795 & $\begin{array}{l}\text { IGLL3P, LRP5L, } \\
\text { CRYBB2P1 }\end{array}$ \\
\hline Congenital anomaly & 25695469 & 25903543 & 208.1 & 4 & Dup & 0.689 & $\begin{array}{l}\text { IGLL3P, LRP5L, } \\
\text { CRYBB2P1 }\end{array}$ \\
\hline Prematurity, arthrogryposis & 23643164 & 23756873 & 113.7 & 3 & Dup & 0.591 & $\begin{array}{l}\text { BCR, } \\
\text { ZDHHC8P1, } \\
\text { CES5AP1 }\end{array}$ \\
\hline
\end{tabular}

CNV, copy number variants.

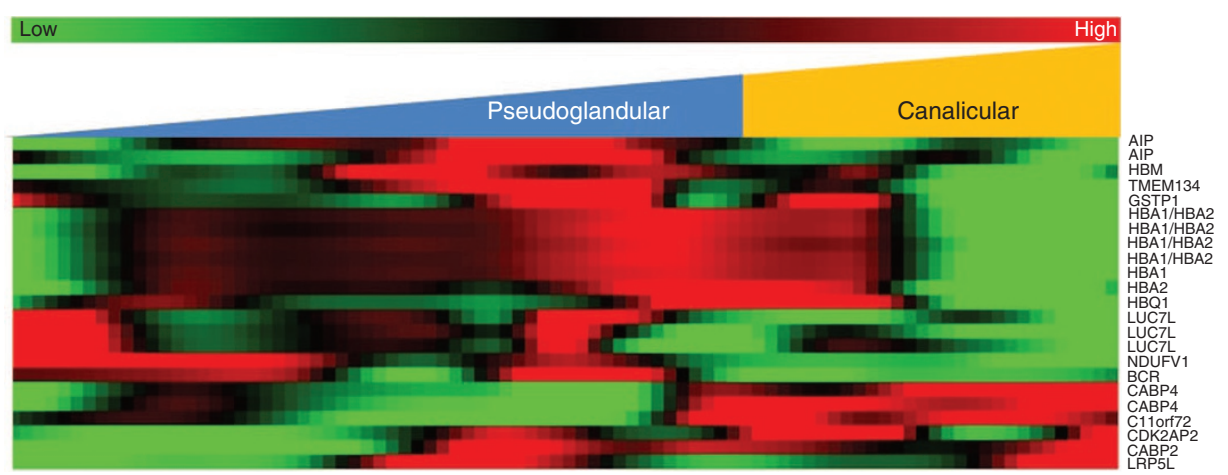

Figure 1. Expression level of genes during normal human lung development. Twenty-one genes from recurrent CNV regions were assessed for expression levels in our database of normal human lung development (20). Fifteen genes (71.4\%) showed change in expression between the pseudoglandular and canalicular stages $(P<0.05)$, coincident with the timing of preterm birth for subjects with the greatest risk of BPD. Shown here are data for 23 probesets representing 15 genes. Rows represent the probesets and columns represent sample ordered chronologically left to right. Red indicates over expression and green indicates under expression. CNV, copy number variants. 


\section{Pathway Analysis}

To test for biological processes represented by genes residing within $\mathrm{CNV}$ regions, we performed pathway analysis using the 21 genes present in the identified recurrent CNV regions. We identified three canonical pathways including aryl hydrocarbon receptor signaling, xenobiotic metabolism signaling, and glutathione-mediated detoxification (Table 5). We also identified development- and disease-related processes, which were significantly over-represented by these genes (see Supplementary Table S1 online).

\section{DISCUSSION}

To the best of our knowledge, this is the first retrospective study using clinical DNA microarray data for the identification of $\mathrm{CNV}$ associated with BPD. Genomic structural variation is classically defined as deletion, duplication, and other genomic alterations larger than $1 \mathrm{~kb}(22)$. CNV can be classified as genic $\mathrm{CNV}$, rare $\mathrm{CNV}$, and common polymorphic CNV. We studied all $\mathrm{CNV}$ larger than $1 \mathrm{~kb}$ in our analysis, and identified three $\mathrm{CNV}$ regions that are recurrent in multiple subjects with BPD. All three of these recurrent CNV occurred in BPD subjects at a frequency significantly greater than at least one control population, either preterm or full-term subjects lacking chronic lung disease. While a recent single-nucleotide polymorphism arraybased study failed to identify any statistically significant CNV associated with BPD (23), it has been reported that the sensitivity and specificity for $\mathrm{CNV}$ detection from single-nucleotide polymorphism arrays are lower than that of array comparative genomic hybridization platforms (24). While this is a small study, our data suggest that genes within or adjacent to these loci warrant further study as genetic susceptibility factors for BPD.

The recurrent $\mathrm{CNV}$ we report here occur on three separate chromosomes and collectively encompass 21 genes. Only one of these genes, GSTP1 located at 11q13.2, has been previously reported for association with BPD (25). However, no association was observed in a subsequent study (26). The CNV at this locus have also been reported to be affected in different types of cancer (27-29). Interestingly, the LRP5 gene is located $838 \mathrm{~kb}$ downstream of the 11q13.2 locus, and has been shown to regulate development of lung microvessels and alveolar formation through the angiopoietin-Tie2 pathway (30). Lrp5, a Wnt coreceptor, is also a genetic driver of lung fibrosis in mice, and a marker of disease progression and severity in humans with idiopathic pulmonary fibrosis (31). We suggest that genes adjacent to the CNV reported here warrant further consideration for association with BPD.

The CNV at locus 16p13.3 directly involve the human alpha globin gene cluster region. Tryptases are serine proteases

Table 5. List of statistically significant $(P<0.05)$ canonical pathways identified by Ingenuity pathways analysis (IPA) software

\begin{tabular}{lll}
\hline Canonical pathways & $P$ value & Gene \\
\hline Aryl hydrocarbon receptor signaling & 0.0035 & GSTP1, AIP \\
Xenobiotic metabolism signaling & 0.0126 & GSTP1, AIP \\
Glutathione-mediated detoxification & 0.0191 & GSTP1 \\
\hline
\end{tabular}

secreted by mast cells, which themselves are commonly associated with allergic responses and asthma (32). Additionally, mast cell gene expression and mast cell accumulation have recently been associated with BPD severity in humans, and in animal models of disease (11). The genes encoding mast cellspecific tryptases (e.g., TPSAB1, TPSB2, TPSD1, etc.) are clustered about $1.02-1.06 \mathrm{Mb}$ downstream of the recurrent $\mathrm{CNV}$ on locus $16 \mathrm{p} 13.3$.

The recurrent $\mathrm{CNV}$ region at 22q11.23-q12.1 involves two loci separated by $1.9 \mathrm{Mb}$, and includes six genes. This CNV are not rare in the general population $(>1 \%$ frequency in the normal population), and so are considered a polymorphic CNV region. Recent studies have shown that polymorphic regions have important functional consequences and can be associated with disease susceptibility $(18,21)$. For example, CNV at locus 8p23.1, a well-known polymorphic region containing the beta-defensin cluster, is associated with common multifactorial diseases such as Crohn's disease and psoriasis $(33,34)$. Interestingly, deletion of 22q11.23-q12.1 was previously reported in a premature baby who died $1 \mathrm{~d}$ after birth (35).

$\mathrm{CNV}$ can cause disease through a deletion or duplication, if they encompass dosage sensitive genes. Furthermore, CNV or other genomic structural variations that are located at a distance from dosage sensitive genes can affect expression through position effects or deletion of key regulatory elements (22). Dosage sensitive genes can cause disease alone or in combination with other genetic or environmental factors (22). In a previous study, $17 \%$ of the variation in gene expression was explained by CNV (36). We directly assessed expression of 21 genes located within recurrent $\mathrm{CNV}$ using a previously published data set describing global gene expression in lung tissue from subjects with BPD and appropriate controls (11), but found no significant changes.

Human lung development is divided into five different stages: embryonic, pseudoglandular, canalicular, saccular, and alveolar. Preterm infants born prior to or at the end of the canalicular stage, or at less than 29 wks of gestational age are at the greatest risk of BPD. Using previously published normal human lung development expression data (20), we found 15 of the 21 genes (71.4\%) located within recurrent CNV loci displayed significant changes $(P<0.05)$ in expression between the pseudoglandular and the canalicular stage of lung development. This indicates that these genes might have role in normal lung development.

$\mathrm{BPD}$ is a multifactorial disease and many factors contribute to the pathogenesis of disease, including hyperoxia and excessive production of free radicals. Using Ingenuity pathways analysis analysis tools, we identified 3 canonical pathways represented by the 21 genes present in the observed recurrent $\mathrm{CNV}$ regions, which included aryl hydrocarbon receptor signaling, xenobiotic metabolism signaling, and glutathionemediated detoxification. Recently, it was shown that the aryl hydrocarbon receptor signaling pathway is dysregulated in the lungs of neonatal mice exposed to hyperoxia, a treatment that results in BPD-like pathology (37). Exposure to high concentrations of supplemental oxygen generates free radicals which 
may cause tissue damage in preterm infants due to poorly developed antioxidant systems (38). Free radicals also induce lipid peroxidation. The glutathione-mediated detoxification pathway plays an important role in the protection of tissues from toxic effects of free radicals and lipid peroxidation.

There may in fact be a precedent for associations between $\mathrm{CNV}$ and lung development abnormalities, as are observed in BPD. Schloo et al. (39) reported on cases of Down syndrome with abnormal pulmonary development characterized by decreased alveolar complexity. These individuals had a common CNV involving duplication of an entire chromosome (trisomy 21). Deutsch et al. (40), also reported the identification of trisomy 21 in one case with characteristic alveolar abnormalities and no heart disease. It is important to note that trisomy 21 was not present in any of the subjects described in this study.

There are some limitations in this study worth noting. BPD diagnosis was obtained through review of the electronic medical records, which was restricted to the presence or absence of a clinical diagnosis of BPD, but not the criteria used for defining BPD. The absence of quantitative criteria available for determination of BPD diagnosis is a weakness that could introduce variability within the study design. However, it is worth noting that all subjects described in this study were from a single site. Also, since the clinical indications for $\mathrm{CNV}$ testing for all the subjects studied were heterogeneous (and did not include BPD), this may have introduced bias in the association of CNV with BPD. Importantly, there was no common indication for CNV testing in BPD subjects; the only consistent clinical problem in those subjects is a clinical diagnosis of BPD. Similarly, no consistent clinical indication for CNV testing was observed in either set of control subjects. We conclude that the novel $\mathrm{CNV}$ described in this study may contribute to the identification of subjects with BPD. Replication and validation of these studies are the focus of current efforts.

\section{MATERIALS AND METHODS}

\section{Clinical DNA Database and Microarray Platform}

The study was approved by the Institutional Review Board at the University of Rochester and included a retrospective analysis of the clinical DNA microarray database of our institution. This database includes data from approximately 2,800 subjects tested between 2008 and 2013. All subjects included in our studies provided consent for future research purposes. The DNA microarray experiments were performed using the Agilent $4 \times 44 \mathrm{~K}$ (Agilent Technologies, Santa Clara, CA), ISCA v1.0, and v2.0 platforms. Commercially available pooled DNA (Male \& Female; Promega Corporation, Madison, WI) was used as control DNA.

\section{Subjects and Controls}

We searched our deidentified DNA microarray database using specific terms of interest (e.g., BPD, prematurity, lung, and pulmonary) and identified a set of 177 subjects at risk for a clinical diagnosis of BPD and appropriate controls. Ascertainment of the presence or absence of a clinical diagnosis of BPD involved a review of the clinical problems list for each subject in the electronic medical record system. Among the 177 at-risk subjects, 19 premature infants received a clinical diagnosis of BPD. We identified two sets of control subjects; a group of infants born prematurely, but who had no evidence of lung disease $(n=23)$, and a group of full-term subjects who had no evidence of either prematurity or lung disease $(n=41)$ (Figure 2). The median gestational age for premature subject diagnosed with BPD was 30.5

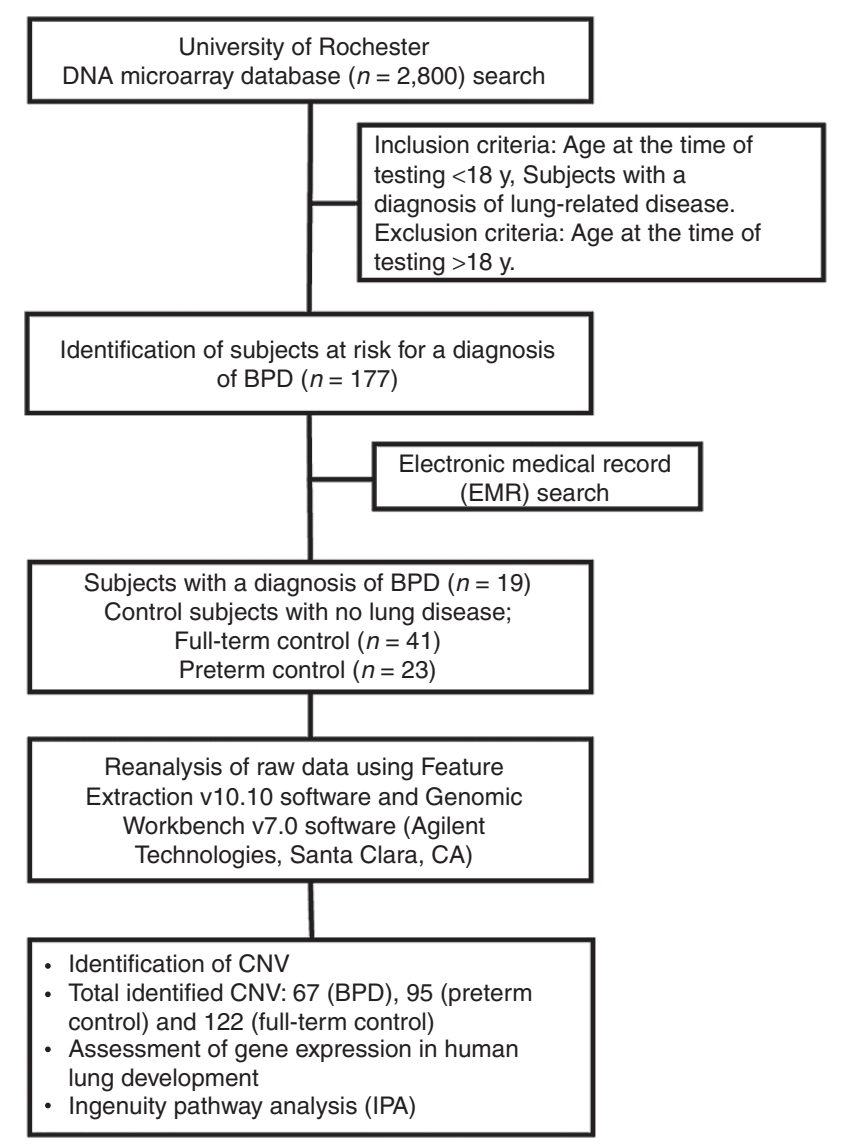

Figure 2. Workflow of identification of CNV associated with bronchopulmonary dysplasia. The steps includes (i) search of DNA microarray database $(n=2,800)$ for identification of subjects at risk for a diagnosis of BPD, (ii) review of medical records of potential subjects $(n=177)$ for ascertainment of the presence and absence of a clinical diagnosis of BPD, (iii) re-analysis of raw DNA microarray data of BPD subjects and control groups, and finally (iv) identification of CNV, assessment of human lung development gene expression database and pathway analysis using genes present in the identified recurrent CNV regions. BPD, bronchopulmonary dysplasia; CNV, copy number variants.

wks and median gestational age for premature subject used as control was 33.5 wks. We further applied two tailed $t$-test and the difference in gestational age in BPD subjects and preterm control subjects was statistically not significant $(P=0.088)$.

\section{Data Analysis}

The raw DNA microarray results (tiff image files) were processed using Feature Extraction software v10.10 (Agilent Technologies) and analyzed using Genomic Workbench software v7.0 (Agilent Technologies) using manufacturer's recommended analysis settings. To control for small variations, we used an extra aberration filter; the minimum number of probes present in an aberrant region was set at 3 (gain or loss) with the minimum absolute level of average log2 ratio equal to 0.25 . The Derivative $\log 2$ Ratio Spread for all subjects was in the excellent range $(\leq 0.20)$.

Analysis reports from each case were generated by Genomic Workbench software and included chromosome coordinates (start and end) of CNV, cytoband, log ratio, and genes present within each $\mathrm{CNV}$. The cytoband location and genes within the identified locus were verified using chromosomal coordinates of CNV in the UCSC genome browser (41) and human genome NCBI build 37 (hg19). $\mathrm{CNV}$ loci affected in more than one subject and the minimal affected region across subjects, were determined manually. Differences in the frequency of CNV between BPD case and control groups at any given locus were assessed by Fisher's exact test. 


\section{Assessment of Existing Normal Lung Development Microarray Expression}

For assessment of human lung development gene expression, we examined data from our previously published data set characterizing genome-wide expression in normal fetal lung tissue from 53 to 130 $\mathrm{d}$ of estimated gestational age (ref. (20) and GEO). For 21 genes of interest, we extracted time-specific summarized expression values, and unadjusted $t$-test $P$ values for differential expression when comparing the pseudoglandular vs. canalicular stages. Data were linked across data sets according to the NCBI Gene Symbol.

\section{Pathway Analysis}

To test for pathways and biological processes represented by genes residing within recurrent $\mathrm{CNV}$ regions, we performed analysis using Ingenuity pathways analysis software (QIAGEN, Valencia, CA).

\section{SUPPLEMENTARY MATERIAL}

Supplementary material is linked to the online version of the paper at http:// www.nature.com/pr

\section{ACKNOWLEDGMENTS}

The authors thank Carl T. D'Angio for helpful advice to develop the IRB protocol. The authors also thank Ann Marie Scorsone for help in reviewing the electronic medical records and IRB-related matters.

\section{STATEMENT OF FINANCIAL SUPPORT}

This study was funded by a Strong Children's Research Center (SCRC) Research Grant, University of Rochester, Rochester, United States.

Disclosure: The authors have no conflicts of interest to report.

\section{REFERENCES}

1. Banks-Randall B, Ballard RA. Bronchopulmonary dysplasia: Avery's diseases of the newborn. In: Taeusch HW, Ballard RA, and Gleason CA eds. Avery's Diseases of the Newborn, 8th edn. Philadelphia: Saunders, 2005:723-36.

2. Goldenberg RL, Culhane JF, Iams JD, Romero R. Epidemiology and causes of preterm birth. Lancet 2008;371:75-84.

3. Hilgendorff A, Reiss I, Ehrhardt H, Eickelberg O, Alvira CM. Chronic lung disease in the preterm infant. Lessons learned from animal models. Am J Respir Cell Mol Biol 2014;50:233-45.

4. Baraldi E, Filippone M. Chronic lung disease after premature birth. N Engl J Med 2007;357:1946-55.

5. Bhandari A, Bhandari V. Biomarkers in bronchopulmonary dysplasia. Paediatr Respir Rev 2013;14:173-9.

6. Abman SH, Mourani PM, Sontag M. Bronchopulmonary dysplasia: a genetic disease. Pediatrics 2008;122:658-9.

7. Bhandari V, Gruen JR. The genetics of bronchopulmonary dysplasia. Semin Perinatol 2006;30:185-91.

8. Bhandari V, Bizzarro MJ, Shetty A, et al.; Neonatal Genetics Study Group. Familial and genetic susceptibility to major neonatal morbidities in preterm twins. Pediatrics 2006;117:1901-6.

9. Lavoie PM, Dubé MP. Genetics of bronchopulmonary dysplasia in the age of genomics. Curr Opin Pediatr 2010;22:134-8.

10. Thompson A, Bhandari V. Pulmonary biomarkers of bronchopulmonary dysplasia. Biomark Insights 2008;3:361-73.

11. Bhattacharya S, Go D, Krenitsky DL, et al. Genome-wide transcriptional profiling reveals connective tissue mast cell accumulation in bronchopulmonary dysplasia. Am J Respir Crit Care Med 2012;186:349-58.

12. Pietrzyk JJ, Kwinta P, Wollen EJ, et al. Gene expression profiling in preterm infants: new aspects of bronchopulmonary dysplasia development. PLoS One 2013;8:e78585.

13. Hadchouel A, Durrmeyer X, Bouzigon E, et al. Identification of SPOCK2 as a susceptibility gene for bronchopulmonary dysplasia. Am J Respir Crit Care Med 2011;184:1164-70.

14. Wang H, St Julien KR, Stevenson DK, et al. A genome-wide association study (GWAS) for bronchopulmonary dysplasia. Pediatrics 2013;132: 290-7.

15. Ambalavanan N, Cotten CM, Page GP, et al.; Genomics and Cytokine Subcommittees of the Eunice Kennedy Shriver National Institute of Child Health and Human Development Neonatal Research Network. Integrated genomic analyses in bronchopulmonary dysplasia. J Pediatr 2015;166: 531-7.e13.

16. Conrad DF, Hurles ME. The population genetics of structural variation. Nat Genet 2007;39:Suppl 7:S30-6.

17. Frazer KA, Murray SS, Schork NJ, Topol EJ. Human genetic variation and its contribution to complex traits. Nat Rev Genet 2009;10:241-51.

18. Girirajan S, Campbell CD, Eichler EE. Human copy number variation and complex genetic disease. Annu Rev Genet 2011;45:203-26.

19. Hehir-Kwa JY, Pfundt R, Veltman JA, de Leeuw N. Pathogenic or not? Assessing the clinical relevance of copy number variants. Clin Genet 2013;84:415-21.

20. Kho AT, Bhattacharya S, Tantisira KG, et al. Transcriptomic analysis of human lung development. Am J Respir Crit Care Med 2010;181:54-63.

21. Hollox EJ. Copy number variation of beta-defensins and relevance to disease. Cytogenet Genome Res 2008;123:148-55.

22. Feuk L, Carson AR, Scherer SW. Structural variation in the human genome. Nat Rev Genet 2006;7:85-97.

23. Hoffmann TJ, Shaw GM, Stevenson DK, et al. Copy number variation in bronchopulmonary dysplasia. Am J Med Genet A 2014;164A:2672-5.

24. Oldridge DA, Banerjee S, Setlur SR, Sboner A, Demichelis F. Optimizing copy number variation analysis using genome-wide short sequence oligonucleotide arrays. Nucleic Acids Res 2010;38:3275-86.

25. Manar MH, Brown MR, Gauthier TW, Brown LA. Association of glutathione-S-transferase-P1 (GST-P1) polymorphisms with bronchopulmonary dysplasia. J Perinatol 2004;24:30-5.

26. Karagianni P, Rallis D, Fidani L, et al. Glutathion-S-transferase P1 polymorphisms association with broncopulmonary dysplasia in preterm infants. Hippokratia 2013;17:363-7.

27. Shi ZZ, Jiang YY, Hao JJ, et al. Identification of putative target genes for amplification within 11q13.2 and 3q27.1 in esophageal squamous cell carcinoma. Clin Transl Oncol 2014;16:606-15.

28. Sarova I, Brezinova J, Zemanova Z, et al. Characterization of chromosome 11 breakpoints and the areas of deletion and amplification in patients with newly diagnosed acute myeloid leukemia. Genes Chromosomes Cancer 2013;52:619-35.

29. Sárová I, Březinová J, Zemanová Z, et al. Rearrangement of 11q13.2 region in two patients with acute myeloid leukemia. Leuk Res 2013;37:479.

30. Mammoto T, Chen J, Jiang E, et al. LRP5 regulates development of lung microvessels and alveoli through the angiopoietin-Tie2 pathway. PLoS One 2012;7:e41596.

31. Lam AP, Herazo-Maya JD, Sennello JA, et al. Wnt coreceptor Lrp5 is a driver of idiopathic pulmonary fibrosis. Am J Respir Crit Care Med 2014;190:185-95.

32. Soto D, Malmsten C, Blount JL, Muilenburg DJ, Caughey GH. Genetic deficiency of human mast cell alpha-tryptase. Clin Exp Allergy 2002;32: 1000-6.

33. Hollox EJ, Barber JC, Brookes AJ, Armour JA. Defensins and the dynamic genome: what we can learn from structural variation at human chromosome band 8p23.1. Genome Res 2008;18:1686-97.

34. Stuart PE, Hüffmeier U, Nair RP, et al. Association of $\beta$-defensin copy number and psoriasis in three cohorts of European origin. J Invest Dermatol 2012;132:2407-13.

35. Hoeffding Louise K, Kock Kirsten F, Johnsen Iben G, Hansen T, Werge T. Usefulness of the SNP microarray technology to identify rare mutations in the case of perinatal death. Case Rep Perinat Med 2015;4:61-4.

36. Haraksingh RR, Snyder MP. Impacts of variation in the human genome on gene regulation. J Mol Biol 2013;425:3970-7.

37. Bhattacharya S, Zhou Z, Yee M, et al. The genome-wide transcriptional response to neonatal hyperoxia identifies Ahr as a key regulator. Am J Physiol Lung Cell Mol Physiol 2014;307:L516-23.

38. Trindade CEP, Rugolo LMSS. Free radicals and neonatal diseases. NeoReviews 2007;8:e522-e32.

39. Schloo BL, Vawter GF, Reid LM. Down syndrome: patterns of disturbed lung growth. Hum Pathol 1991;22:919-23.

40. Deutsch GH, Young LR, Deterding RR, et al.; Pathology Cooperative Group; ChILD Research Co-operative. Diffuse lung disease in young children: application of a novel classification scheme. Am J Respir Crit Care Med 2007;176:1120-8.

41. Kent WJ, Sugnet CW, Furey TS, et al. The human genome browser at UCSC. Genome Res 2002;12:996-1006. 